\title{
Prevalence of insecticide resistance in field-collected populations of the German cockroach, Blattella germanica (Linnaeus)
} (Dictyoptera: Blattellidae) in Peninsular Malaysia

\author{
Kong-Meng LEE and Chow-Yang LEE* \\ Urban Entomology Laboratory, Vector Control Research Unit, School of Biological Sciences, \\ Universiti Sains Malaysia, 11800 Penang, Malaysia \\ * Corresponding anthor: chowyang@usm.my
}

(Received: 27 May 2002; Accepted: 26 August 2002)

\begin{abstract}
Key words: Blattella germanica, insecticide resistance, Malaysia, gene frequency, discriminating dose
\end{abstract}

\begin{abstract}
Thirty one field-collected strains of German cockroaches, Blattella germanica (L.), collected between February 1997 and March 2000 from various locations in Peninsular Malaysia were screened for insecticide resistance using topical application method against three commonly used insecticides (propoxur, chlorpyrifos and deltamethrin). A discriminating dose ( $\left.\mathrm{LD}_{99}\right)$ obtained from bioassaying a laboratory susceptible strain, was used to determine the prevalence of insecticide-resistant individuals among the field populations tested. Results indicated that both propoxur and deltamethrin resistance patterns were relatively similar, i.e. more than $50 \%$ of the strains screened show low to moderate level of tolerance, while chlorpyrifos resistance is still relatively low among the tested populations. Resistant gene frequencies estimated ranged between 0.01 to $0.78,0.05$ to 0.51 and 0 to 0.86 for propoxur, chlorpyrifos and deltamethrin, respectively.
\end{abstract}

\section{INTRODUCTION}

The German cockroach, Blattella germanica (L.) is an important urban insect pest in many parts of the world. Extensive usage of insecticides against this species has led to serious problems of insecticide resistance. Insecticide resistance in the German cockroach was detected as early as 1952 in Corpus Christi, Texas, USA (Heal et al., 1953) and subsequently numerous incidents of insecticide resistance in the German cockroach have been reported (Webb, 1961; Grayson, 1965; Cornwell, 1968; Bennett and Spink, 1968; Barson and McCheyne, 1979; Cochran, 1987; 1989; Horwood et al., 1991; Rust and Reierson, 1991; Zhai and Robinson, 1991; Lee et al., 1996, 1997, 1999).
In Southeast Asia, the first document of broad spectrum insecticide resistance in the German cockroach was reported by Lee et al. (1996) in Malaysia, where twelve field-collected strains of German cockroach showed low to high resistance to carbamate insecticides (propoxur and bendiocarb), low resistance to organophosphate insecticide (chlorpyrifos) and low to moderate resistance to pyrethroid insecticides (cypermethrin, permethrin, phenothrin and deltamethrin), based on resistance ratios obtained from comparison of $\mathrm{LD}_{50}$ values with that of a susceptible strain. Over the last few years, more incidents on insecticide resistance in the German cockroach in this region were detected and documented (Lee, 1997, 1998; Lee and Lee, 1998; Lee et al., 1997, 1999, 2000; Choo et al., 2000). 
The ability to accurately detect the presence of resistant individuals in a population is crucial in a resistance management program. Dose-mortality regression method (topical application) was often reported to give higher resistance ratio values than time-mortality method (WHO glass jar contact) (Scott et al., 1986; Millio et al., 1987; Zhai and Robinson, 1992).

Discriminating dose (DD) is defined as the insecticidal dose that will kill all susceptible individuals. Insecticide bioassays utilizing a DD is more efficient in detecting the presence of resistant individuals in the population, than bioassays using a series of different concentrations or time intervals (Roush and Miller, 1986). Here, we report insecticide resistance in the field populations of German cockroach by using discriminating dose. This method may not be able to elucidate the level of resistance in the German cockroach, but is extremely useful to detect potential development of insecticide resistance in the cockroach populations, even though the number of resistant individuals are only at an extremely small fraction of the population.

\section{Materials AND Methods}

A total of 31 field populations of the German cockroach were collected from various premises in Peninsular Malaysia from 1997 to 2000 to be screened for insecticide resistance. They were reared for

Table 1. Information on strains of field-collected populations of the German cockroach, Blattella germanica (L.) used in this study.

\begin{tabular}{|c|c|c|c|}
\hline Strain & Collection site & City & Date of collection \\
\hline BUSM & University cafeteria & Penang & 20 Nov 1997 \\
\hline BBR & Hotel kitchen & Penang & 11 Jan 1999 \\
\hline CIGO & Restaurant's kitchen & Kuala Lumpur & 28 Dec 1998 \\
\hline $\mathrm{COP}$ & Hotel kitchen & Penang & 21 Sept 1999 \\
\hline $\mathrm{CP}$ & Hotel kitchen & Penang & 2 Nov 1998 \\
\hline $\mathrm{CT}$ & Hotel kitchen & Kuantan & 18 Aug 1999 \\
\hline EMP & Cruise ship & - & 2 Dec1999 \\
\hline FBR & Hotel kitchen & Penang & 20 Jan 2000 \\
\hline GCJB & Hotel kitchen & Johor Bahru & 29 Dec 1998 \\
\hline GCPG & Hotel kitchen & Penang & 29 June 1999 \\
\hline GL & Hotel kitchen & Kuantan & 18 Aug 1999 \\
\hline GT & Hotel kitchen & Kuantan & 3 Aug 1999 \\
\hline HUSM & University cafeteria & Penang & 20 Nov 1997 \\
\hline IE & Express bus & - & 24 May 1998 \\
\hline IHKL & Hotel kitchen & Kuala Lumpur & 15 Oct 1999 \\
\hline Ita & Hotel kitchen & Penang & 13 Dec 1999 \\
\hline KTM & Train & - & $10 \operatorname{Mar} 2000$ \\
\hline LHFA & Restaurant's kitchen & Kuala Lumpur & 25 June 1998 \\
\hline LHFB & Restaurant's kitchen & Kuala Lumpur & 27 June 1998 \\
\hline Mal & Hotel kitchen & Kuala Lumpur & 16 Dec 1998 \\
\hline Mar & Hotel kitchen & Penang & 25 June 1998 \\
\hline ML & Hotel kitchen & Kuala Lumpur & 13 Feb 1997 \\
\hline MT & Hotel kitchen & Penang & 25 Jan 1999 \\
\hline PK & Hotel kitchen & Kuantan & 17 Aug 1999 \\
\hline PRPG & Hotel kitchen & Penang & 6 Jan 1999 \\
\hline Raja & Hotel kitchen & Kuantan & 18 Aug 1998 \\
\hline Sedap A & Food court & Johor Bahru & 5 Jan 1999 \\
\hline Selesa & Restaurant's kitchen & Johor Bahru & 5 Jan 1999 \\
\hline Sun & Hotel kitchen & Penang & 23 Nov 1998 \\
\hline Yao & Bakery & Penang & 5 Dec 1998 \\
\hline ZT & Food court & Kuala Lumpur & 28 Nov 1999 \\
\hline
\end{tabular}


a generation under laboratory conditions of $26.5+0.5^{\circ} \mathrm{C}, 55 \pm 5.0 \%$ relative humidity and a photoperiod of $12: 12(\mathrm{~L}: \mathrm{D})$ prior to insecticidal tests. For comparison, a susceptible strain, ICI, obtained from Zeneca Agrochemicals, U. K. was used as a standard in this study. Information on the fieldcollected strains are shown in Table 1.

Three commonly used insecticides, namely propoxur, chlorpyrifos and deltamethrin were tested against the fieldcollected insects. Technical grade propoxur (99.5\%) (Bayer AG, Germany), chlorpyrifos (95.9\%) (Dow Agrosciences Malaysia) and deltamethrin (96.1\%) (Aventis Environmental Health, Malaysia) diluted in analytical grade acetone were used in this study. These insecticides were the three most common insecticides used in pest control operation in Malaysia. They are usually treated in the form of residual sprays.

$\mathrm{LD}_{99}$ values for each insecticide were obtained by testing against a susceptible strain, ICI. A series of 5-7 concentrations of each insecticide, that caused 1-100\% mortality, were used where $1.0 \mu \mathrm{l}$ of the pre-determined concentrations of insecticides in acetone was applied topically onto the ventral mesothorax of $\mathrm{CO}_{2}$-anesthetized male cockroaches. Each concentration was replicated three times with 10 insects per replicate. Control cockroaches were treated with acetone. Upon treatment, the insects were placed inside clean petri dishes and provided with food and water. Mortality was recorded at 48 hours post-treatment. Data were pooled and subjected to probit analysis (Finney, 1971) according to the procedures described by Robertson and Preistler (1992) using the POLO-PC program (LeOra Software, 1997).

Upon obtaining the $\mathrm{LD}_{99}$ for each insecticide, all 31 strains of field collected populations were topically treated with $1 \mu l$ of $\mathrm{LD}_{99}$ of each insecticide. Treated cockroaches were then placed into clean petri dishes and provided with food and water. Mortality of the cockroaches were recor- ded at 48 hours post-treatment. Depending on availability, a total of 60-100 adult males were tested.

Resistant gene frequency was estimated by assuming the populations were in Hardy-Weinburg equilibrium (Falconer and Mackay, 1996) using the measured frequency of homozygous susceptibles in each strain. Dead cockroaches from treatment with discriminating dose were considered as homozygous susceptible individuals.

\section{Results AND Discussion}

The $\mathrm{DD}\left(\mathrm{LD}_{99}\right)$ values obtained from the bioassays against the susceptible strain, ICI for propoxur, chlorpyrifos and deltamethrin were $3.027 \mu \mathrm{g} /$ male, $2.540 \mu \mathrm{g} /$ male and $0.056 \mu \mathrm{g} / \mathrm{male}$, respectively.

Overall results indicated that insecticide resistance in the field populations of German cockroach in Malaysia was generally prevalent (Fig. 1). Although propoxur has been reduced in usage in response to control failure, nevertheless, resistant genes have remained aloft in the population of the field strains, even under the absence of insecticide selection pressure. The discriminating dose of propoxur caused mortality range from 5.0 to $97.14 \%$ in the field populations tested (Table 2). This suggested low to high level of propoxur resistance. Propoxur-resistant gene frequency was estimated between 0.01 to 0.78. Earlier, Lee et al. $(1996,2000)$ reported that extensive usage and heavy reliance on propoxur have caused the development of high level of resistance to this insecticide in many populations of the German cockroach which were collected in the mid 1990s, in Malaysia. The results from this study suggested that propoxur resistance is still a very wide-spread problem, despite drastic reduction in its usage for several years.

Discriminating dose of chlorpyrifos killed between 24.0 and $90.0 \%$ of the field populations tested (Table 2, Fig. 1). Generally, resistance to chlorpyrifos was rela- 

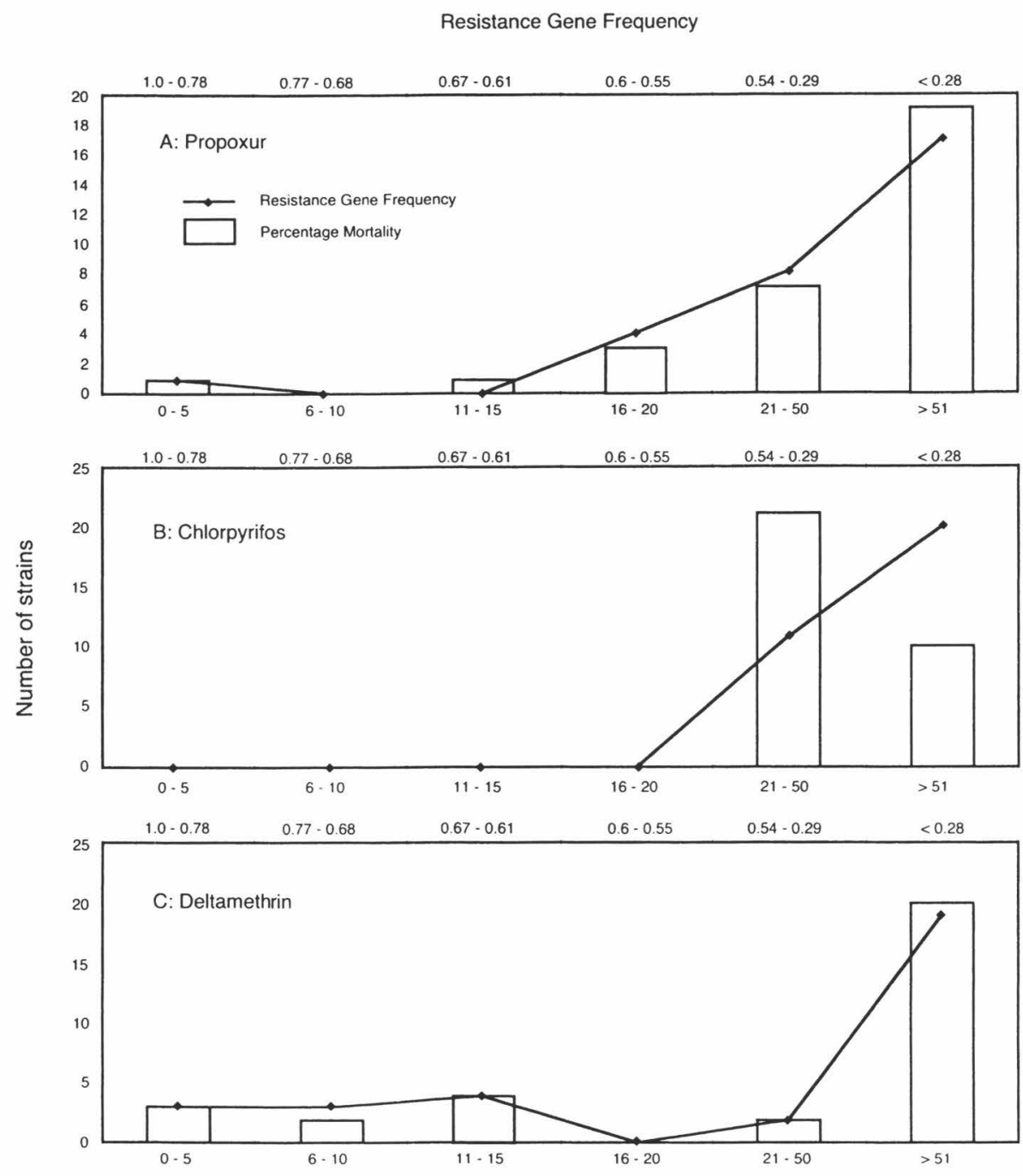

Percentage Mortality

Fig. 1. Mortality of cockroaches treated with discriminating dosages of propoxur (A), chlorpyrifos (B) and deltamethrin (C). The number of strains are indicated by each bar adds up to 31 . The line graph indicates frequency of resistant genes in the same mortality categories as the bar graph. The number of strains in the line graph also adds up to 31 .

tively low with gene frequency estimated at 0.05 to 0.51 . Only $29.0 \%$ of the total field populations tested carried at least $10 \%$ chlorpyrifos-resistant gene in the populations. Cochran (1995) reported that it was possible to detect insecticide resistance in a population of German cockroach if the frequency of resistant gene present in the population was at least $10 \%$.

Cochran (1973) suggested that the discriminating dose technique could enable the separation of the heterozygous and susceptible individuals, but not the resistant individuals. These findings corresponded well with the findings of Lee et al. $(1996,1999)$ where low resistance to organophosphate was recorded in field populations of the German cockroach. Cochran (1989) reported that high physiological resistance to organophosphate insecticides (chlorpyrifos and diazinon) was not detected although extensive usage of those in- 
Table 2. Percentage mortality of the field-collected Blattella germanica after treatment with discriminating dose of propoxur, chlorpyrifos and deltamethrin.

\begin{tabular}{|c|c|c|c|c|c|c|}
\hline \multirow{2}{*}{ Strain } & \multicolumn{2}{|c|}{ Propoxur } & \multicolumn{2}{|c|}{ Chlorpyrifos } & \multicolumn{2}{|c|}{ Deltamethrin } \\
\hline & $n$ & $\%$ mortality & $n$ & $\%$ mortality & $n$ & $\%$ mortality \\
\hline BUSM & 100 & 96.00 & 90 & 73.33 & 100 & 94.00 \\
\hline BBR & 60 & 80.00 & 100 & 43.00 & 100 & 60.00 \\
\hline CIGO & 70 & 60.00 & 90 & 33.33 & 100 & 8.00 \\
\hline $\mathrm{COP}$ & 100 & 55.00 & 90 & 44.44 & 100 & 13.00 \\
\hline $\mathrm{CP}$ & 100 & 55.00 & 100 & 24.00 & 100 & 8.00 \\
\hline $\mathrm{CT}$ & 100 & 20.00 & 100 & 67.00 & 100 & 5.00 \\
\hline EMP & 100 & 5.00 & 100 & 31.00 & 100 & 30.00 \\
\hline FBR & 100 & 30.00 & 100 & 58.00 & 100 & 45.00 \\
\hline GCJB & 100 & 54.00 & 90 & 32.00 & 100 & 70.00 \\
\hline GCPG & 100 & 40.00 & 90 & 71.11 & 100 & 75.00 \\
\hline GL & 90 & 16.67 & 100 & 40.00 & 80 & 81.25 \\
\hline GT & 100 & 15.00 & 100 & 55.00 & 100 & 63.00 \\
\hline HUSM & 70 & 90.00 & 90 & 63.33 & 100 & 100.00 \\
\hline $\mathrm{IE}$ & 100 & 54.00 & 100 & 90.00 & 100 & 65.00 \\
\hline IHKL & 100 & 42.00 & 90 & 45.56 & 100 & 54.00 \\
\hline Ita & 70 & 40.00 & 100 & 51.00 & 100 & 78.00 \\
\hline KTM & 100 & 16.00 & 90 & 52.22 & 100 & 2.00 \\
\hline LHFA & 100 & 78.00 & 100 & 54.00 & 100 & 94.00 \\
\hline LHFB & 70 & 84.29 & 100 & 63.00 & 100 & 99.00 \\
\hline Mal & 70 & 50.00 & 80 & 68.75 & 100 & 12.00 \\
\hline Mar & 100 & 42.00 & 90 & 87.00 & 100 & 12.00 \\
\hline ML & 100 & 68.00 & 100 & 67.00 & 100 & 15.00 \\
\hline MT & 70 & 61.43 & 100 & 50.00 & 70 & 77.14 \\
\hline $\mathrm{PK}$ & 100 & 48.00 & 100 & 48.00 & 100 & 53.00 \\
\hline PRPG & 100 & 60.00 & 100 & 75.00 & 100 & 87.00 \\
\hline Raja & 70 & 97.14 & 100 & 77.00 & 100 & 63.00 \\
\hline Sedap A & 100 & 25.00 & 100 & 65.00 & 100 & 10.00 \\
\hline Selesa & 100 & 90.00 & 100 & 76.00 & 90 & 88.89 \\
\hline Sun & 100 & 70.00 & 100 & 65.00 & 100 & 76.00 \\
\hline Yao & 100 & 86.00 & 100 & 78.00 & 100 & 5.00 \\
\hline$Z T$ & 100 & 17.00 & 100 & 55.00 & 100 & 60.00 \\
\hline
\end{tabular}

secticides had been recorded, and therefore could still provide effective control of the German cockroach. Holbrook et al. (1999) also reported low to moderate resistance to chlorpyrifos in a more recent study. Our current findings showed that the use of chlorpyrifos to control the German cockroach in Malaysia could still provide good control as the frequency of resistant genes detected in field-collected populations was relatively low.

Results with deltamethrin showed a mortality range of 2.0 to $100.0 \%$ among the field-collected German cockroaches with an average mortality of $51.72 \%$ (Table 2, Fig. 1). Resistance to pyrethroids have been numerously reported and incidents of control failure with this class of insecticide are on the rise (Gammon et al., 1981; Scott et al., 1986; Hemingway et al., 1993; Zhai and Robinson, 1992, 1996; Scharf et al., 1997; Lee, 1997; Lee et al., 1996, 1997, 2000; Lee and Lee 1998). This insecticide still display a good efficacy against the German cockroach where $64.5 \%$ of the field strains fall in the range mortality rates of $>51 \%$. Estimation of resistant gene of the field populations showed that the majority of the cockroach populations have yet to develop serious resistance to this insecticide where $>60 \%$ of the field strains exhibited frequency of 
resistant gene of less than 0.28 . The frequency of resistant gene ranged from 0 to 0.86 . Nonetheless, if the usage of the deltamethrin continues indiscriminately, the rate of frequency of the resistant gene would possibly increase in magnitude.

The results obtained suggest that the phenomenon of insecticide resistance is very common among broad-spectrum insecticides since all tested populations showed resistance to all classes of insecticide used in this study. A sensitive method is therefore crucial for early detection of resistant individuals. The method used in this study was able to serve this purpose relatively well. However, caution should be taken into account when dealing with the establishment of the discriminating dose because any error could affect the results of the detection of resistance to insecticides where susceptible strains might be wrongly treated as resistant strains. Another aspect that should be taken into consideration is the selection of susceptible strain to establish the discriminating dose. A clear distinction between the occurrence of natural tolerance in a population and the resistant genes has to be determined to avoid confusion when dealing with the level of insecticide resistance.

\section{ACKNOWLEDGEMENTS}

The authors thank L. C. Lee and S. Y. Lim for technical assistance and the following pest control companies for helping with the field cockroach collections: Flick Pest, Pest Dynamics, Rentokil Initial and Ridpest. This study was partially funded by the Malaysian Government IRPA Programme (06-02-05-9008).

\section{REFERENCES}

Barson, G. and McCheyne, N. G. 1979. A test for detecting resistance to bendiocarb in the German cockroach, Blattella germanica (L.). Int. Pest Control, 21: $42-43$.

Bennett, G. W. and Spink, W. T. 1968. Insecticide resistance of German cockroaches from various areas of Louisiana. J. Econ. Entomol., 61: 426-431.

Choo, L. E. W., Tang, C. S., Pang, F. Y. and Ho, S. H. 2000. Comparison of two bioassay methods for determining deltamethrin resistance in German cockroaches (Blattodea: Blattellidae). J. Econ. Entomol., 93: 905-910.

Cochran, D. G. 1973. Inheritance and linkage of pyrethrins resistance in the German cockroach. J. Econ. Entomol., 66: 27-30.

Cochran, D. G. 1987. Effects of synergist on bendiocarb and pyrethrin resistance in the German cockroach (Dictyoptera: Blattellidae). J. Econ. Entomol. 80: 728-732.

Cochran, D. G. 1989. Monitoring for insecticide resistance in field-collected strains of the German cockroach (Dictyoptera: Blattellidae). J. Econ. Entomol., 82: 336-341.

Cochran, D. G. 1995. Insecticide resistance. In: Understanding and Controlling the German Cockroach (ed. Rust, M. K., Owens, J. M. and Reierson, D. A.), pp. 171-192, Oxford University Press, New York.

Cornwell, P. B. 1968. The Cockroach. Vol. 1. 313 pp. Hutchinson Press, London.

Falconer, D. S. and Mackay, T. F. C. 1996. Introduction to Quantitative Genetics. 464 pp. Longman Scientific and Technical, New York.

Finney, D. J. 1971. Probit Analysis. Third Edition. 333 pp. Cambridge University Press, London.

Gammon, D. W., Brown, M. A. and Casida, J. E. 1981. Two classes of pyrethroid action in the cockroach. Pestic. Biochem. Physiol., 15: 181-191.

Grayson, J. M. 1965. Resistance to three organophosphorus insecticides in strains of the German cockroach from Texas. J. Econ. Entomol., 68: 956-958.

Heal, R. E., Nash, K. B. and Williams, M. 1953. An insecticide-resistant strain of the German cockroach from Corpus Christi. J. Econ. Entomol., 46: 385-386.

Hemingway, J., Dunbar, S. J., Monro, A. G. and Small, G. J. 1993. Pyrethroid resistance in German cockroaches (Dictyoptera: Blattellidae): resistance levels and underlying mechanisms. J. Econ. Entomol., 86: 1631-1638.

Holbrook, G. L., Roebuck, J., Moore, C. B. and Schal, C. 1999. Prevalence and magnitude of insecticide resistance in the German cockroach (Dictyoptera: Blattellidae). In: Proceedings of the Third International Conference on Urban Pests (ed. Robinson, W. 
H., Rettich, F. and Rambo, G. W.), pp. 141-146, Graficke zavody Hronov, Prague.

Horwood, M. A., Toffolon, R.B. and Preece, R. M. 1991. Resistance to deltamethrin in Blattella germanica (L.) (Blattodea: Blattellidae). J. Aust. Entomol. Soc., 30: 256.

Lee, C. Y. 1997. Insecticide resistance and its underlying mechanisms in the German cockroach, Blattella germanica (L.) (Dictyoptera: Blattellidae). J. Biosci., 8: 156-172.

Lee, C. Y. 1998. Control of insecticide-resistant German cockroaches, Blattella germanica (L.) (Dictyoptera: Blattellidae) in food-outlets with hydramethylnon-based bait stations. Trop. Biomed., 15: 45-51.

Lee, C. Y., Hemingway, J., Yap, H. H. and Chong, N. L. 2000. Biochemical characterization of insecticide resistance in the German cockroach, Blattella germanica, from Malaysia. Med. Vet. Entomol., 14: 1118.

Lee, C. Y., Lee, L. C., Ang, B. H. and Chong, N. L. 1999. Insecticide resistance in the German cockroach from hotels and restaurants in Malaysia. In: Proceedings of the $3^{\text {rd }}$ International Conference on Urban Pests (ed. Robinson, W. H., Rettich, F. and Rambo, G.W.), pp. 171-182, Graficke zavody Hronov, Prague.

Lee, C. Y., Yap, H. H. and Chong, N. L. 1997. Elevated esterase detection in insecticide resistant German cockroaches (Dictyoptera: Blattellidae) using modified Pasteur-Georghiou's filter-paper method. Trop. Biomed., 14: 81-86.

Lee, C. Y., Yap, H. H., Chong, N. L. and Lee, R. S. T. 1996. Insecticide resistance and synergism in fieldcollected German cockroaches (Dictyoptera: Blattellidae) in Peninsular Malaysia. Bull. Entomol. Res., 86: 675-682.

Lee, L. C. and Lee, C. Y. 1998. Characterization of pyrethroid and carbamate resistance in a Malaysian field-collected strain of the German cockroach, Blattella germanica (L.) (Dictyoptera: Blattellidae). Trop. Biomed., 15: 1-9.
LeOra Software. 1997. POLO-PC: Probit And Logit Analysis. LeOra Software, California, USA.

Milio, J. F., Koehler, P. G. and Patterson, R. S. 1987. Evaluation of three methods for detecting chlorpyrifos resistance in German cockroach (Orthoptera: Blattellidae) populations. J. Econ. Entomol., 80: 4446.

Robertson, J. L. and Preistler, H. K. (1992). Pesticide Bioassays with Arthropods. CRC Press, Boca Raton.

Roush, R. T. and Miller, G. L. 1986. Considerations for design of insecticide resistance monitoring programs. J. Econ. Entomol., 79: 293-298.

Rust, M. K. and Reierson, D. A. 1991. Chlorpyrifos resistance in German cockroaches (Dictyoptera: Blattellidae) from restaurants. J. Econ. Entomol., 84: 736-740.

Scharf, M. E., Kaakeh, W. and Bennett, G. W. 1997. Changes in an insecticide resistant field-population of German cockroach following exposure to an insecticide mixture. J. Econ. Entomol., 90: 38-48.

Scott, J. G., Ramaswamy, S. B., Matsumura, F. and Tanaka, K. 1986. Effect of method of application on resistance to pyrethroid insecticides in Blattella germanica (Orthoptera: Blattellidae). J. Econ. Entomol., 79: 571-575.

Webb, J. E. 1961. Resistance of some species of cockroaches to organic insecticides in Germany and France. J. Econ. Entomol., 54: 805-806.

Zhai, J. and Robinson, W. H. 1991. Pyrethroid resistance in a field population of German cockroach, Blattella germanica (L.). Jpn. J. Sanit. Zool., 42: 241244.

Zhai, J. and Robinson, W. H. 1992. Measuring cypermethrin resistance in the German cockroach (Orthoptera: Blattellidae). J. Econ. Entomol., 85: 348351.

Zhai, J. and Robinson, W. H. 1996. Instability of cypermethrin resistance in a field population of the German cockroach (Orthoptera: Blattellidae). J. Econ. Entomol., 89: 332-336. 